\title{
Selective management strategy of interrupted aortic arch mitigates left ventricular outflow tract obstruction risk
}

\author{
Bahaaldin Alsoufi, MD, ${ }^{\mathrm{a}}$ Brian Schlosser, BS, RDCS, ${ }^{\mathrm{b}}$ Courtney McCracken, PhD, ${ }^{\mathrm{b}}$ \\ Ritu Sachdeva, MBBS, ${ }^{b}$ Brian Kogon, MD, ${ }^{\mathrm{a}}$ William Border, MBChB, MPH, ${ }^{\mathrm{b}}$ William T. Mahle, MD, ${ }^{\mathrm{b}}$ and \\ Kirk Kanter, MD
}

\begin{abstract}
Background: Left ventricular outflow tract obstruction (LVOTO) is an important problem after interrupted aortic arch (IAA) repair, especially when early reoperation is required during infancy. Several anatomic factors have been identified that increase LVOTO risk; surgical strategies such as concomitant resection of the conal septum or left ventricular outflow tract (LVOT) bypass (single-stage Yasui operation, or staged Norwood procedure, followed by the Rastelli procedure) have been proposed for such patients.
\end{abstract}

Methods: From 2002 to 2013, a total of 77 neonates underwent IAA repair. Based on the presence of anatomic substrate for LVOTO, patients underwent standard IAA repair and ventricular septal defect closure $(\mathrm{n}=53 ; 69 \%)$, concomitant conal resection $(\mathrm{n}=7 ; 9 \%)$, or LVOT bypass $(\mathrm{n}=17 ; 22 \%$, staged in 14$)$. We analyzed anatomic details that influence procedure choice, and explored reoperation risk and survival after repair.

Results: Neonates who had conal resection or LVOT bypass had significantly smaller aortic valve and subaortic areas, as well as a trend toward a higher prevalence of type B IAA, aberrant right subclavian artery, and bicuspid aortic valve. Freedom from LVOT reoperation was $96 \%$ and $80 \%$, at 1 and 8 years, respectively, and was lower after conal resection $(P=.008)$. Most LVOT reoperations $(73 \%)$ were for discrete subaortic obstruction. Survival was $86 \%$ at 8 years, and was not related to procedure choice, whereas freedom from all-cause reoperation was $65 \%$ at 8 years, and was higher after standard repair $(P=.029)$.

Conclusions: Compared with published reports, this selective management strategy, which is customized to the degree of aortic valve and subaortic area narrowing, has mitigated and delayed LVOTO risk. With this tailored approach, most LVOT reoperations occur after infancy and are commonly for discrete subaortic obstruction. The effect of aortic valve and LVOT narrowing on increased LVOTO risk is neutralized with LVOT bypass procedures; however, it continues to be the highest after conal resection, suggesting the superiority of LVOT bypass, compared with enlargement in neonates who are at risk of developing LVOTO. (J Thorac Cardiovasc Surg 2016;151:412-21)

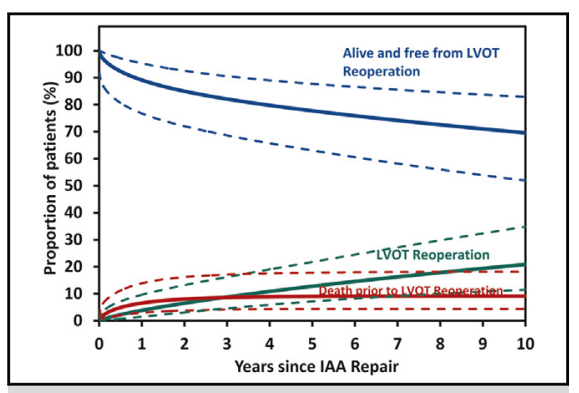

Depiction of risk levels of death, and of LVOT reoperation, after IAA repair.

\section{Central Message}

A selective IAA repair strategy that addresses LVOTO risk mitigates, delays, and decreases the complexity of subsequent LVOT reoperations.

\section{Perspective}

Our review of outcomes of a selective management approach that addresses LVOT obstruction risk at the time of initial IAA repair showed that, compared with historic reports, this management strategy has mitigated LVOT reoperation risk, prolonged duration until reoperation, decreased the complexity of reoperations, and neutralized the effect of morphology on late LVOT reoperation risk.

See Editorial Commentary page 422.
From the a Division of Cardiothoracic Surgery, Department of Surgery; and ${ }^{\mathrm{b}}$ Division of Cardiology, Department of Pediatrics, Children's Healthcare of Atlanta, Emory University School of Medicine, Atlanta, Ga.

Funding for this work was institutional only.

Read at the 95th Annual Meeting of The American Association for Thoracic Surgery, Seattle, Washington, April 25-29, 2015.

Received for publication April 25, 2015; revisions received Sept 1, 2015; accepted for publication Sept 3, 2015; available ahead of print Oct 29, 2015.

Address for reprints: Bahaaldin Alsoufi, MD, Division of Cardiothoracic Surgery, Department of Surgery, Emory University School of Medicine, Children's Healthcare of Atlanta, 1405 Clifton Road, NE, Atlanta, GA 30322 (E-mail: balsoufi@ hotmail.com). 0022-5223/\$36.00

Copyright (c) 2016 by The American Association for Thoracic Surgery

http://dx.doi.org/10.1016/j.jtcvs.2015.09.060
Surgical management of interrupted aortic arch (IAA) has evolved in the past few decades, and single-stage neonatal IAA repair, with closure of the ventricular septal defect, has

Scanning this QR code will take you to supplemental figures for this article. To view the AATS 2015 Webcast, see the URL at the end of the article. 


\section{Abbreviations and Acronyms \\ CHSS = Congenital Heart Surgeons' Society \\ $\mathrm{CI}=$ confidence interval \\ ECMO = extracorporeal membrane oxygenation \\ IAA $=$ interrupted aortic arch \\ LVOT $=$ left ventricular outflow tract \\ LVOTO $=$ left ventricular outflow tract obstruction}

become the standard management strategy. ${ }^{1-9}$ Despite improved early survival, left ventricular outflow tract obstruction (LVOTO) remains a common and challenging development after IAA repair and is associated with significant morbidity and mortality, especially when early reintervention for LVOTO is required in infancy., $2,5,9-14$ Studies have demonstrated that reoperation for LVOTO after IAA repair is associated with high mortality and increased risk for subsequent reoperations for recurrent LVOTO. These results indicate that IAA is a chronic disease that is associated with persistent attrition and reoperation risks. ${ }^{2,4,9,14}$ In addition, studies have demonstrated that survival, freedom from reoperation, and quality of life are correlated with the level of complexity of surgical reoperations for recurrent LVOTO, in that more-complex reoperations are associated with worse outcomes. ${ }^{4,13,14}$

The definition and diagnostic criteria used for LVOTO after IAA repair differ in the literature, and several series have reported various morphologic and echocardiographic risk factors for development of LVOTO., ${ }^{2,5,13,15-18}$ Although the definition of LVOTO has not been uniform, LVOTO risk has clearly increased in patients who have a smaller aortic valve annulus and LVOT, which are commonly due to posterior deviation of the conal septum. As a result, several surgical strategies have been proposed to address obstruction risk at the time of the initial IAA repair in those who have the morphologic substrate to develop subsequent LVOTO. Those surgical strategies included concomitant resection of the conal septum, the RossKonno procedure, or the Damus-Kaye-Stansel procedure to completely bypass the narrow LVOT. ${ }^{2,4,5,14,19-29}$

At our institution, we adopted an aggressive strategy to apply those more complex operations in neonates who are at risk of developing LVOTO. We hypothesized that this management strategy, given that it is customized to cardiac morphology, affects the timing and type of reoperation for LVOTO after IAA repair. In the current study, we aim to describe the morphologic details that influenced the initial choice of procedure and to examine survival and LVOTO reoperation risk at our institution.

\section{METHODS}

\section{Patients}

Between 2002 and 2013, a total of 77 neonates with IAA underwent surgery at Children's Healthcare of Atlanta, Emory University, identified using our institutional surgical database. Given that the primary goal of the study was to assess the influence of surgical repair strategy on the development of LVOTO, patients who had IAA that was associated with ventricular septal defect or an aortopulmonary window were included, whereas patients who had IAA that was associated with truncus arteriosus, transposition of the great arteries, atrioventricular septal defect, or single ventricle were not included. Demographic, morphologic, clinical, operative, and hospital details were abstracted from the medical records for analysis. Approval of this study was obtained from our hospital's institutional review board, and the requirement for individual consent was waived for this observational study.

\section{Echocardiographic Data Collection}

All preoperative echocardiograms were retrospectively reviewed by a single echocardiographer, who is one of the investigators. The following morphologic features were reported: the type of IAA, the presence or absence of aberrant origin of the right subclavian artery from the descending aorta or pulmonary artery, the type of ventricular septal defect, the presence of malalignment of the infundibular septum, and the number of aortic valve cusps. In addition, the following dimensions were measured: the diameter of the aortic valve annulus, the diameter of the mitral valve annulus, the cross-sectional area of the left ventricular outflow tract (LVOT), the diameter of the aortic root, and the diameter of both the ascending and descending aorta.

The definition and risk factors for LVOT have varied in the literature. For comparison between patients who underwent different initial procedures, the following parameters were examined: aortic valve annulus diameter; aortic valve $z$-score; aortic valve indexed cross-sectional area; aortic valve minus weight; LVOT diameter; LVOT indexed cross-sectional area; averaged LVOT/descending aorta diameter; and ascending aorta $z$-score.

\section{Statistical Analysis}

Data are described as means with SDs, medians with interquartile ranges, or frequencies and percentages, as appropriate. Patient demographics and echocardiographic characteristics were compared among IAA repair groups (standard, LVOT enlargement, LVOT bypass) using Kruskal-Wallis tests and $\chi^{2}$ analysis. Time-dependent outcomes (death, LVOT reoperation, arch reoperation, all-cause cardiac reoperation) after IAA repair were parametrically modeled. Parametric probability estimation for time-dependent outcomes uses models based on multiple, overlapping phases of risk available for use with the SAS system (SAS Institute, Inc, Cary, NC). The HAZARD procedure uses maximum likelihood estimates to resolve risk distribution of time-to-event in as many as 3 phases of risk (early, constant, and late). For the outcome LVOT reoperation, events were scattered throughout the duration of the follow-up period; thus, a late-phase model provided the best fit to the data.

The following events occurred primarily during the early years after initial repair: mortality, mortality prior to LVOT reoperation, and arch reoperation. As a result, an early-phase mortality model provided the best parametric representation of survival. Finally, for the outcome all-cause reoperation, several events occurred early (especially arch reoperation), whereas other events were scattered throughout the duration of followup; thus, the survival distribution was best characterized by an early- and late-phase model. Competing-risks analysis was performed to parametrically model the probability, over time to occurrence, of 2 mutually exclusive endpoints: LVOT reoperation and death before LVOT reoperation; the remainder of patients were alive and free from LVOT reoperation. All statistical analyses were performed using SAS, version 9.3 (SAS Institute).

\section{RESULTS}

\section{Patient Characteristics}

During the study period, 77 neonates with IAA underwent surgical repair at our institution; 45 were male $(58 \%)$. The median (interquartile range) age at the time 
of surgery was 7 (range: 5-10) days; and the median weight was 3.0 (interquartile range: $2.5-3.4) \mathrm{kg}$, with $20(26 \%)$ patients weighing $\leq 2.5 \mathrm{~kg}$. Gestational age was known in 76 patients; $12(16 \%)$ were born prematurely at $\leq 36$ weeks' gestation. Forty-six $(60 \%)$ patients had genetic syndromes, in most cases, DiGeorge syndrome $(\mathrm{n}=41 ; 53 \%)$. The additional 5 patients with genetic syndromes had 1 of the following: Cat Eye syndrome $(\mathrm{n}=2)$; Dandy-Walker syndrome $(\mathrm{n}=1)$; Klippel-Feil syndrome $(\mathrm{n}=1)$; and CHILD (congenital hemidysplasia with ichthyosiform erythroderma and limb defects) syndrome $(\mathrm{n}=1)$.

\section{Operative Details}

All procedures were performed through a midline sternotomy. Cardiopulmonary bypass was established via the following: aortic cannulation that was performed through a 3.5-mm polytetrafluoroethylene graft that was sutured to the base of the innominate artery (or right common carotid artery in patients with aberrant origin of the right subclavian artery); an additional arterial cannula that was placed in the ductus arteriosus (while snaring the branch pulmonary arteries); and bicaval venous cannulation. The left ventricle was decompressed by venting through a purse-string suture anterior to the right superior pulmonary vein, or through the left atrial appendage. Deep hypothermia was utilized (in a range of $18-25^{\circ} \mathrm{C}$ ). Arch reconstruction was performed using selective cerebral perfusion in all cases. Antegrade cardioplegia was administered using the Del Nido solution. All arch repairs were performed using patch augmentation, and all ventricular septal defects $(n=74)$ were closed using a patch. Four patients had concomitant aortopulmonary window; 3 of them had no ventricular septal defect.

Overall, $53(69 \%)$ patients had standard IAA repair with arch augmentation, closure of the ventricular septal defect, and/or aortopulmonary window without any LVOT intervention. In addition, 7 (9\%) patients had concomitant LVOT enlargement, with resection of the conal septum. In those patients, conal resection was performed through the tricuspid valve. ${ }^{10}$ The remaining $17(22 \%)$ patients had a DamusKaye-Stansel-based LVOT bypass that either was staged with an initial Norwood operation $(\mathrm{n}=14 ; 18 \%)$ or was single stage with a Yasui operation $(n=3 ; 4 \%)$. The source of pulmonary blood flow at the time of the Norwood operation was a right-ventricle-to-pulmonary-artery "Sano" shunt in 10 of 14, and an aortic-to-pulmonary "modified BlalockTaussig" shunt in 4 of 14 patients. In 3 patients who had the Yasui operation, the right-ventricle-to-pulmonary-artery continuity was established with a homograft conduit. Intraoperative transesophageal echocardiography was routinely used for assessment of the repair.

Comparison of patient characteristics (these were comparable), cardiopulmonary bypass, and cardiac ischemic durations among patients who had different surgical procedures showed that cardiopulmonary bypass duration was longer in patients who underwent the Norwood and/or Yasui operations (Table 1). On the other hand, patients who underwent standard repair had a higher incidence of tricuspid aortic valve, and a trend for higher incidence of type A interruption, and for lower incidence of aberrant origin of the right subclavian artery (Table 2). Additionally, echocardiographic measurements showed that patients who had standard repair had larger parameters of LVOT, aortic annulus, and ascending aorta sizes.

In patients who had the staged LVOT bypass procedures starting with the Norwood operation $(\mathrm{n}=14)$, the secondstage reoperation consisted of ventricular septal defect baffle closure and right-ventricle-to-pulmonary-artery conduit placement, and was done at a median of 244 days after the Norwood operation (range: 132-810 days). One of those patients had an intermediary Glenn shunt with subsequent completion of the biventricular repair and takedown of the Glenn shunt. One patient was noted to have severe neoaortic valve regurgitation after the second-stage procedure, and required a return on cardiopulmonary bypass for placement of a mechanical prosthesis.

\section{Hospital Events After Initial Surgery}

After surgery, $5(7 \%)$ patients required extracorporeal membrane oxygenation (ECMO) support. One patient required ECMO after standard repair ( 1 of $53 ; 2 \%$ ); this patient weighed $2.5 \mathrm{~kg}$, was in shock, and had both multiorgan failure and necrotizing enterocolitis before surgery. The patient had surgery 1 week later, after stabilization, but needed to return on cardiopulmonary bypass for arch revision, and failed to wean off cardiopulmonary bypass support and eventually died. Additionally, 4 (24\%) patients required ECMO support after LVOT bypass, all after the Norwood operation: 1 patient had cardiac arrest, likely as a result of coronary steal from a $3.5-\mathrm{mm}$ modified Blalock-Taussig shunt. One patient had a 3.5-mm modified BlalockTaussig shunt and had cardiac arrest during attempted percutaneous intervention on the stenotic shunt, and eventually underwent revision to a Sano shunt. Another patient had a 6-mm Sano shunt, had cardiac arrest after chest closure, and was found to have shunt stenosis that required percutaneous intervention. Finally, the fourth of these patients had cardiac arrest after the Norwood procedure, on the same day with a 6-mm Sano shunt for poor ventricular function that improved a few days later. All 4 patients survived to hospital discharge.

Overall, $3(4 \%)$ patients died at the hospital, all of them after standard repair. These mortalities were due to the following: 1 patient failed to wean off cardiopulmonary support requiring ECMO (1 of the 4 just described); 1 patient with Klippel-Feil syndrome had a prolonged intensive-care unit stay owing to tracheal stenosis and developed sepsis and multiorgan failure; and 1 patient with Dandy-Walker syndrome had severe tricuspid valve 
TABLE 1. Comparison of characteristics and operative details for patients in the 3 surgical groups

\begin{tabular}{|c|c|c|c|c|c|}
\hline Characteristic/operative detail & $\begin{array}{l}\text { Overall } \\
(\mathbf{n}=77)\end{array}$ & $\begin{array}{l}\text { Standard repair } \\
\quad(\mathbf{n}=\mathbf{5 3})\end{array}$ & $\begin{array}{c}\text { LVOT enlargement } \\
(n=7)\end{array}$ & $\begin{array}{c}\text { LVOT bypass } \\
(\mathbf{n}=\mathbf{1 7})\end{array}$ & $P$ value \\
\hline Age (d) & $7(5-10)$ & $7(5-10)$ & $8(5-11)$ & $8(5-10)$ & .9108 \\
\hline Weight $(\mathrm{kg})$ & $3.0(2.5-3.4)$ & $3.0(2.3-3.3)$ & $3.4(2.6-3.5)$ & $3.2(2.7-3.4)$ & .1884 \\
\hline Weight $>2.5 \mathrm{~kg}$ & $57(74.0)$ & $36(67.9)$ & $6(85.7)$ & $15(88.2)$ & .2245 \\
\hline Prematurity & $12(15.8)$ & $8(15.4)$ & $3(42.9)$ & $1(5.9)$ & .1010 \\
\hline Genetic syndromes & $46(59.7)$ & $30(56.6)$ & $5(71.4)$ & $11(64.7)$ & .7070 \\
\hline DiGeorge syndrome & $41(53.3)$ & $26(49.1)$ & $5(71.4)$ & $10(58.8)$ & .4746 \\
\hline Perfusion time $(\mathrm{min})$ & $151(141-170)$ & $144(134-155)$ & $154(141-214)$ & $179(166-242)$ & $<.0001$ \\
\hline Crossclamp time (min) & $80(73-93)$ & $80(75-91)$ & $80(78-91)$ & $88(58-94)$ & .9807 \\
\hline
\end{tabular}

Values are median (25th percentile-75th percentile), or $\mathrm{n}(\%)$, unless otherwise indicated. LVOT, Left ventricular outflow tract.

regurgitation on postoperative echocardiogram and had cardiac arrest soon after surgery, but was not considered an ECMO candidate owing to comorbidities and family directives.

\section{Freedom From LVOT Reoperation}

Freedom from LVOT reoperation was examined after completion of intracardiac repair of IAA. The index date was the date of initial surgery for patients who had standard repair, IAA repair plus concomitant LVOT enlargement, or a Yasui operation; the index date was the date of completion of the second-stage biventricular repair in those who had an initial Norwood operation.

The hazard of LVOT reoperation was characterized by the presence of steady early, constant, and late phases of risk, slightly higher in the early phase, but persistent thereafter. The parametric estimate of freedom from LVOT reoperation was $96 \%$ (95\% confidence interval [CI]: $93 \%-97 \%)$ at 1 year; $86 \%(95 \%$ CI: $81 \%-89 \%)$ at 5 years; and 76\% (95\% CI: 69\%-82\%) at 10 years.
Freedom from LVOT reoperation was lower after IAA plus a concomitant LVOT enlargement procedure than it was after standard repair or LVOT bypass, with a 1-year freedom from LVOT reoperation of $84 \%$ (vs 97\% for standard repair and $98 \%$ for LVOT bypass), and a 5-year freedom from LVOT reoperation of $52 \%$ (vs $89 \%$ for standard repair and $93 \%$ for LVOT bypass); $P=.008$ (Figure 1; and Figure E1, $A$ and $B$ ).

Competing risks analysis after initial surgery was performed, with the events being death before LVOT reoperation, and LVOT reoperation; the remaining patients were alive and free from LVOT reoperation. The hazard of mortality before LVOT reoperation was characterized by the presence of an early phase of risk that decreased substantially thereafter. The hazard of LVOT reoperation was characterized by the presence of steady early, constant, and late phases of risk. Competing risks analysis showed that at 1 year after surgery, $7 \%$ had died, 4\% had undergone required LVOT reoperation, and $89 \%$ remained alive without LVOT reoperation. At 5 years after surgery, these

TABLE 2. Comparison of cardiac morphology and echocardiographic measurements for patients in the 3 surgical groups

\begin{tabular}{|c|c|c|c|c|}
\hline Echo parameters & $\begin{array}{c}\text { Standard repair } \\
\quad(n=53) \\
\end{array}$ & $\begin{array}{c}\text { LVOT enlargement } \\
(\mathrm{n}=7)\end{array}$ & $\begin{array}{l}\text { LVOT bypass } \\
\quad(n=17) \\
\end{array}$ & $P$ value \\
\hline IAA type & & & & .0863 \\
\hline A & $13(24.5)$ & $0(0.0)$ & $1(5.9)$ & \\
\hline B & $40(75.5)$ & $7(100.0)$ & $15(88.2)$ & \\
\hline $\mathrm{C}$ & $0(0.0)$ & $0(0.0)$ & $1(5.9)$ & \\
\hline Aberrant origin of the right subclavian artery & $22(41.5)$ & $4(57.1)$ & $12(70.6)$ & .0882 \\
\hline Aortic valve cusps & & & & .0288 \\
\hline Atretic & $0(0.0)$ & $0(0.0)$ & $2(11.8)$ & \\
\hline Bicuspid & $31(60.8)$ & $6(85.7)$ & $13(76.5)$ & \\
\hline Tricuspid & $20(39.2)$ & $1(14.3)$ & $2(11.8)$ & \\
\hline Aortic valve annulus (cm) & $0.48(0.45-0.54)$ & $0.45(0.33-0.48)$ & $0.40(0.35-0.47)$ & .0005 \\
\hline Aortic valve $z$-score & $-2.88(-3.26$ to -2.03$)$ & $-3.65(-3.96$ to -3.20$)$ & $-4.10(-4.52$ to -3.37$)$ & $<.0001$ \\
\hline Aortic valve annulus minus weight & $2.00(1.50-2.60)$ & $1.10(0.80-1.40)$ & $0.80(0.40-1.20)$ & $<.0001$ \\
\hline Aortic valve indexed cross-sectional area $\left(\mathrm{cm}^{2} / \mathrm{m}^{2}\right)$ & $0.90(0.80-1.14)$ & $0.71(0.52-0.80)$ & $0.57(0.49-0.70)$ & $<.0001$ \\
\hline Average LVOT diameter $(\mathrm{cm})$ & $0.42(0.36-0.47)$ & $0.33(0.25-0.45)$ & $0.34(0.28-0.40)$ & .0140 \\
\hline LVOT indexed cross-sectional area $\left(\mathrm{cm}^{2} / \mathrm{m}^{2}\right)$ & $0.64(0.58-0.83)$ & $0.43(0.32-0.67)$ & $0.37(0.28-0.57)$ & .0018 \\
\hline Average LVOT/descending aorta & $0.65(0.56-0.78)$ & $0.46(0.39-0.55)$ & $0.51(0.44-0.54)$ & .0001 \\
\hline Ascending aorta $z$-score & $-1.30(-1.80$ to -0.79$)$ & $-1.87(-2.08$ to -1.56$)$ & $-1.94(-2.35$ to -1.51$)$ & .0057 \\
\hline Proximal transverse arch $z$-score & $-0.71(-1.36$ to -0.28$)$ & $-1.22(-1.37$ to -0.92$)$ & $-1.37(-1.58$ to -0.75$)$ & .0586 \\
\hline
\end{tabular}

Values are median (25th percentile-75th percentile), or n (\%), unless otherwise indicated. LVOT, Left ventricular outflow tract; IAA, interrupted aortic arch. 


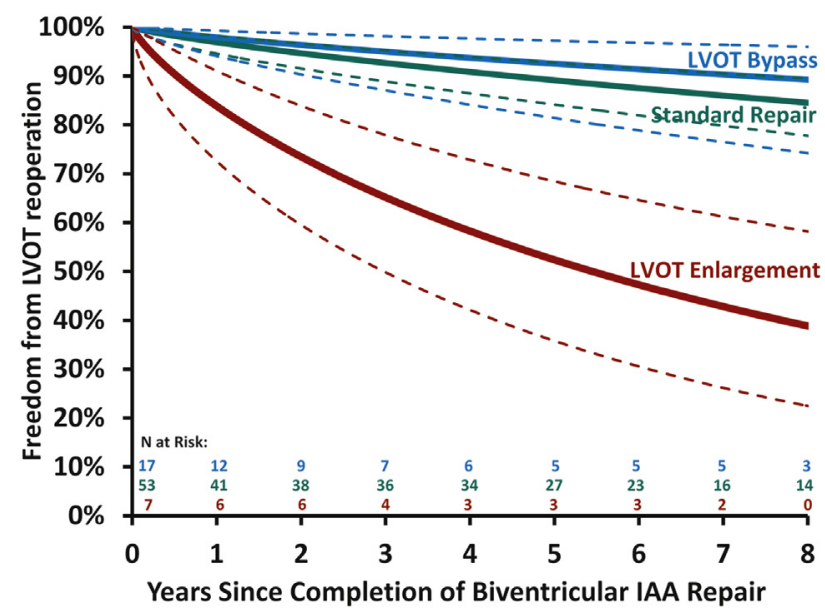

FIGURE 1. Parametric freedom from LVOT reoperation after completion of biventricular IAA repair, stratified by the initial operation: standard repair, IAA repair plus concomitant LVOT enlargement, or LVOT bypass. LVOT, Left ventricular outflow tract; IAA, interrupted aortic arch.

values, respectively, were $9 \%, 13 \%$, and $78 \%$; at 10 years, they were $9 \%, 21 \%$, and $70 \%$ (Figure 2 ).

Overall, 11 patients required LVOT reoperations: 6 had had standard repair; and all included subaortic membrane resection and septal myectomy. Two patients had in addition an aortic valvotomy, and 1 a repair of supra-aortic stenosis. Four of the LVOT reoperations were in patients who had IAA repair plus concomitant LVOT enlargement; these reoperations included subaortic membrane resection and septal myectomy in 2 patients, Ross-Konno operation in 1 patient, and aortic valvotomy plus a modified Konno operation in 1 patient. Finally, 1 LVOT reoperation was in a patient who had an initial Yasui operation and required reoperation to relieve the subaortic obstruction, which

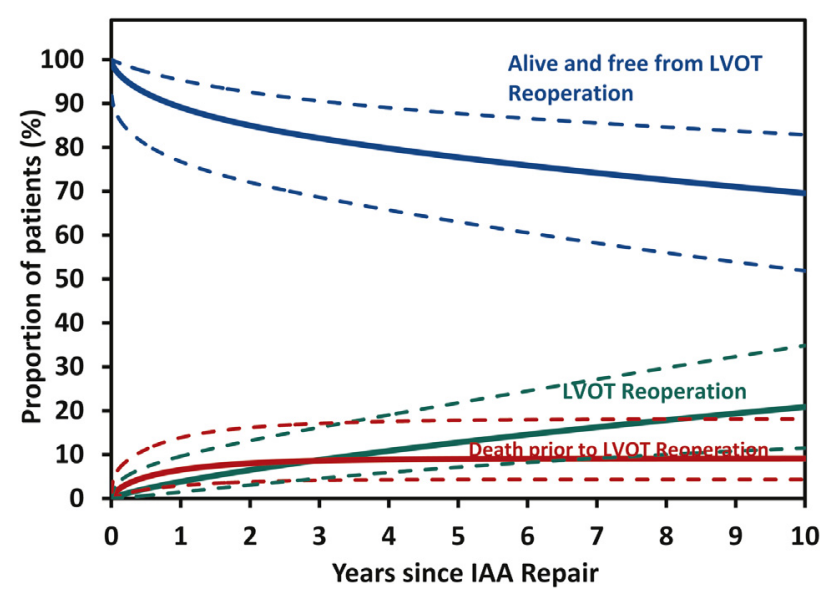

FIGURE 2. Depiction of levels of risk of death, and of LVOT reoperation, after IAA repair; the remaining percentages are patients alive without LVOT reoperation. LVOT, Left ventricular outflow tract; IAA, interrupted aortic arch. was complicated by injury to the neoaortic valve cusps and severe regurgitation, requiring valve replacement and patch augmentation of the LVOT.

\section{Freedom From Arch Reoperation}

The hazard of arch reoperation after IAA repair was characterized by the presence of an early phase of risk that disappeared 1 year after surgery. The parametric estimate of freedom from arch reoperation was $93 \%$ (95\% CI: $90 \%$ $96 \%$ ) at 1 year and 10 years (Figure E2).

\section{Freedom From All-Cause Cardiac Reoperation}

The hazard of all-cause unplanned reoperation after IAA repair was characterized by the presence of a high, early phase of risk, and then lower, but persistent, constant and late phases of risk (Figure E3, $A$ and $B$ ). The parametric estimate of freedom from all-cause reoperation was $86 \%$ (95\% CI: $82 \%-92 \%)$ at 1 year; $73 \%(95 \%$ CI: $67 \%$ $77 \%$ ) at 5 years; and $60 \%(95 \%$ CI: $53 \%-67 \%)$ at 10 years. Freedom from all-cause reoperation was higher after standard repair than after IAA repair plus concomitant LVOT enlargement or LVOT bypass, with a 1-year freedom from all-cause reoperation of $87 \%$ (vs $87 \%$ for LVOT bypass and $80 \%$ for LVOT enlargement), and a 5 -year freedom from all-cause reoperation of $80 \%$ (vs $56 \%$ for LVOT bypass and $53 \%$ for LVOT enlargement); $P=.029$ (Figure 3).

Overall, 22 patients required cardiac reoperations. Eleven cardiac reoperations were in patients who had standard repair, and included the following: subaortic membrane resection and septal myectomy for 6 patients; repair of supra-aortic stenosis and of arch obstruction, each of these for 3 patients; aortic valvotomy and placement of a permanent pacemaker, each of these for 2 patients; and repair of pulmonary vein stenosis for 1 patient. Four cardiac reoperations were in patients who had IAA repair plus concomitant LVOT enlargement; these included subaortic membrane resection and septal myectomy for 2 patients; the Ross-Konno procedure for 1 patient; and aortic valvotomy plus a modified Konno operation for 1 patient. Finally, 7 cardiac reoperations were in patients who had had LVOT bypass; these included conduit change for 5 patients; branch pulmonary artery augmentation for 4 patients; closure of a residual ventricular septal defect for 3 patients; tricuspid valve repair for 2 patients; and repair of subaortic obstruction, complicated by injury to the neoaortic valve cusps that required valve replacement, for 1 patient.

\section{Freedom From Death}

The hazard of death after IAA repair was characterized by the presence of an early phase of risk, with a constant phase of smaller risk and a late phase of very low risk (Figure E4, $A$ and $B$ ). Parametric estimate of overall survival was as follows: $91 \%(95 \%$ CI: $88 \%-94 \%)$ at 


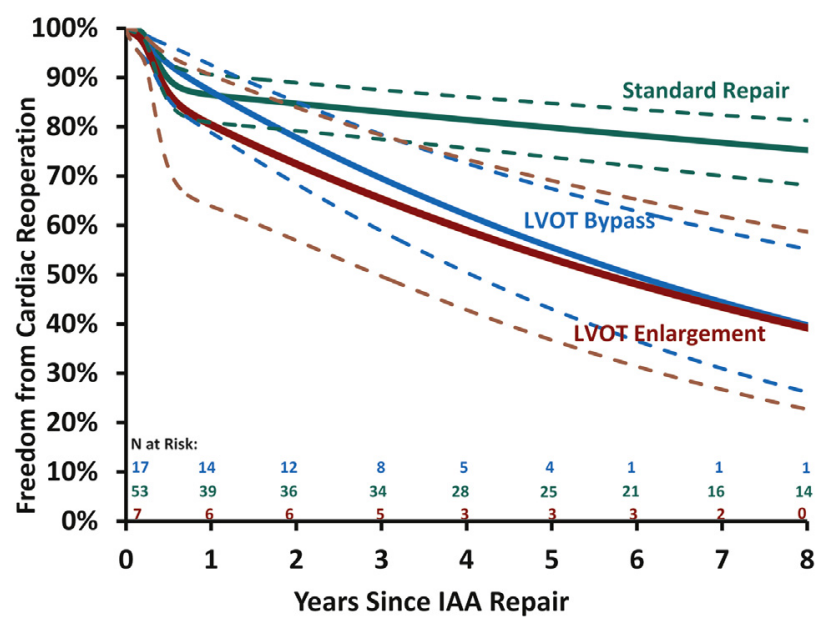

FIGURE 3. Parametric freedom from all-cause cardiac reoperation after IAA repair, stratified by the initial operation: standard repair, IAA repair plus concomitant LVOT enlargement, or LVOT bypass. LVOT, Left ventricular outflow tract; IAA, interrupted aortic arch.

1 year; $86 \%(95 \%$ CI: $82 \%-90 \%)$ at 5 years; and $86 \%$ (95\% CI: $81 \%-90 \%$ ) at 10 years. Survival was comparable among the 3 surgical groups and was $90 \%$ after standard repair, $85 \%$ after IAA repair plus LVOT enlargement, and $76 \%$ after LVOT bypass procedures; $P=.607$ (Figure 4 ).

Overall, 10 patients died. Five deaths occurred after standard repair; these included 3 operative deaths described earlier; 1 late death in a patient who continued to have multilevel LVOT obstruction and left ventricular dysfunction after LVOT reoperation; and 1 late death in a patient who developed recurrent pulmonary vein stenosis after cardiac reoperation. One late death occurred after IAA repair plus concomitant LVOT enlargement in a patient who required LVOT reoperation and the Ross-Konno procedure. Finally, 4 late deaths occurred after LVOT bypass, including 1 in the patient who required replacement of the neoaortic valve at the time of the second-stage operation, 1 in the patient who required LVOT reoperation and replacement of the neoaortic valve after a Yasui operation, 1 in a patient who had persistent biventricular dysfunction after repair, and 1 in a patient who had sepsis after multiple abdominal surgeries.

\section{DISCUSSION}

In our current series, survival was $86 \%$ at 8 years after surgery, which is significantly better than historic reports, and parallel to other recent series that have demonstrated improved life-expectancy after IAA repair. ${ }^{1-4,6,8}$ Despite this superior survival, reoperation for LVOTO continues to be required in $20 \%-40 \%$ of patients. ${ }^{3-5,9-13}$ A large report from the Congenital Heart Surgeons' Society (CHSS) that examined outcomes of 453 neonates who had undergone IAA repair showed that at 16 years after

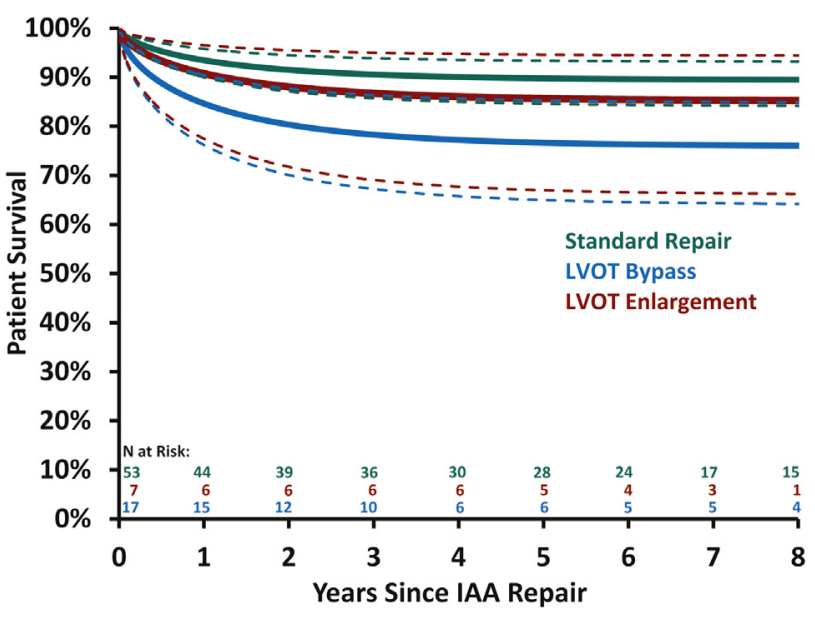

FIGURE 4. Parametric survival after IAA repair, stratified by the initial operation: standard repair, IAA repair plus concomitant LVOT enlargement, or LVOT bypass. LVOT, Left ventricular outflow tract; IAA, interrupted aortic arch.

surgery, $28 \%$ had died, and $34 \%$ had undergone reoperation for LVOTO. Moreover, it showed that patients who underwent an initial reoperation for LVOTO were at risk of mortality and requirement for further reoperations for LVOTO. In that series, 16 years after initial LVOTO reoperation, $37 \%$ had died and $28 \%$ had undergone a second reoperation for LVOTO. ${ }^{4}$ Those findings highlighted the fact that IAA is a chronic disease and is associated with persistent reoperation and attrition risk.

Several morphologic factors have been determined to be associated with LVOTO risk. Those factors include bicuspid aortic valve, aberrant origin of the right subclavian artery, and type B interruption. Those factors have been linked to smaller LVOT, aortic valve, and ascending aorta, which explains the connection to increased LVOTO risk. ${ }^{3-5,10,11,15-18}$ Similarly, this association is evident in our series, wherein patients with smaller LVOT, aortic valve, and ascending aorta dimensions were more likely to undergo LVOT enlargement or bypass procedures at the time of initial repair. Subsequently, the incidence of type B IAA, bicuspid aortic valve, and aberrant origin of the right subclavian artery was higher in those patients than in patients who underwent standard IAA repair alone.

In our current series, the hazard for LVOT reoperation was characterized by steady early, constant, and late risk phases, slightly higher within the first year after surgery. This hazard is different from that in the large Congenital Heart Surgeons' Society report ${ }^{4}$ that showed high early and lower prolonged hazard phases, with most patients requiring LVOT reoperation within the first 6-12 months after IAA repair. This finding indicates that our selective approach has delayed the onset of development of severe LVOTO that requires intervention, with most reoperations occurring after infancy. 
Moreover, the number of complex reoperations performed to address LVOTO in the CHSS study ${ }^{4}$ was high, with many patients requiring complicated procedures, such as complex LVOTO relief, conal resection, ventricular septal defect enlargement, a modified Konno procedure, or a Damus-Kaye-Stansel LVOT bypass procedure. As a result, LVOT reoperations in the CHSS series ${ }^{4}$ were associated with high mortality. For example, 23 of 41 patients who required a late LVOT bypass operation, and 19 of 66 patients who required LVOT obstruction relief, conal resection, or ventricular septal defect enlargement died.

In contrast, our current series showed that most LVOT reoperations were confined to subaortic membrane resection and septal myectomy, although incidence of complex reoperations such as a modified Konno procedure, ventricular septal defect enlargement, aortic valve replacement, or a Ross-Konno procedure was not completely eliminated. In our series, 3 of 7 late mortalities were in patients who had undergone LVOT reoperations, all after complex reoperations such as the Ross-Konno procedure, complex LVOTO relief, and aortic valve replacement. This finding indicates that mortality risk continues to be high after complex LVOT reoperations; however, because those complex reoperations are required less often, the overall mortality after LVOT reoperations has decreased. In addition to the high mortality in patients who required LVOT reoperation in the CHSS study, ${ }^{4}$ those patients were at risk of requiring additional subsequent LVOT reoperations. Although 1 of our late mortalities was related to development of persistent severe LVOTO after LVOT reoperation, this high reoperation risk after initial LVOT reintervention was not evident in our current series, although our follow-up is relatively shorter than that in the CHSS series.

Several procedures that address LVOTO risk at the time of IAA repair have been suggested..$^{3-5,10,19-29}$ One approach is concomitant LVOT enlargement, with septal myectomy and resection of the conal septum at the time of IAA repair and ventricular septal defect closure. ${ }^{3,4,10}$ In a report from Michigan, 15 of 27 patients with the smallest LVOT dimension underwent IAA repair and concomitant LVOT enlargement. Although operative mortality was comparable to that for patients who had standard IAA repair, 6 of 13 survivors required 9 LVOT reoperations. Most of these were limited to subaortic membrane resection, rather than involving complex muscular LVOTO, suggesting the effectiveness of this approach in decreasing complexity and delaying LVOTO risk. ${ }^{10}$ In our series, the results are somewhat comparable, with no operative mortality after IAA repair and LVOT enlargement, and 4 of 7 patients requiring LVOT reoperations, although half of those reoperations were complex, including the RossKonno procedure and a modified Konno procedure.

Another approach that has been suggested to address LVOTO risk is IAA repair, with concomitant LVOT bypass, via a Damus-Kaye-Stansel-type connection of the main pulmonary artery to the aorta, as a means to create a double-outlet left ventricle. ${ }^{3,14,19-23,25,26,28}$ This principle can involve a single-stage approach with simultaneous Rastelli-type baffle closure of the ventricular septal defect, and placement of right-ventricle-to-pulmonary-artery conduit (the Yasui procedure), or a staged approach with an initial Norwood operation and a second-stage Rastellitype baffle closure of the ventricular septal defect, and placement of a right-ventricle-to-pulmonary-artery conduit.

Advantages of the single-stage approach include early restoration of normal physiology of a circulation in series, elimination of prolonged cyanosis and volume load effects of the shunts, with potentially decreased numbers of operations and decreased cost. An advantage of the staged approach is avoiding complex intracardiac repair in small children, placement of a larger right-ventricle-topulmonary-artery conduit at the time of repair, and potentially decreasing the reoperation rate for baffle obstruction in smaller children. ${ }^{3,14,19-23,25,26,28}$ Several centers have reported good results with LVOT bypass procedures, with some preferring the single stage and others preferring the staged approach. The reported outcomes have been comparable, although no large single series is available to evaluate advantages of 1 approach compared with another, owing to institutional bias and small numbers of patients.

Our strategy has evolved to favor the staged approach, and despite the parallel physiology associated with the first-stage Norwood procedure, we had no hospital deaths in our series in this group of patients undergoing the Norwood operation. Our choice of shunt in those patients is a Sano right-ventricle-to-pulmonary-artery shunt, because a right ventriculotomy is going to be required at a secondstage operation.

One concern is that after LVOT bypass procedures, patients may develop baffle obstruction, resulting in recurrent LVOTO. Concomitant enlargement of the ventricular septal defect is commonly performed at the time of baffle closure, and the incidence of recurrent LVOTO resulting from baffle obstruction has been low in our series, with only 1 patient requiring LVOT reoperation to enlarge the ventricular septal defect and revise the patch. Unfortunately, that case was complicated by injury to the neoaortic valve that required valve replacement and was associated with a late death. The low incidence of baffle obstruction in our series echoes results in cases with the Rastelli procedure, in which routine enlargement of the ventricular septal defect at the time of repair has been shown to decrease late LVOTO risk. ${ }^{30}$

The risk of LVOTO after LVOT bypass in our series was low, similar to results from several other institutions, indicating that this approach is very effective in mitigating the risk of LVOTO in patients with anatomic substrate to develop LVOTO after IAA repair. Our series indicates 
that this approach was more successful than LVOT enlargement, in decreasing the LVOT reoperation requirement, especially in patients with the smallest aortic valve and LVOT dimensions.

Nonetheless, LVOT bypass procedures are not free of complications, and problems related to neoaortic valve regurgitation and ventricular dysfunction have affected late outcomes in our series. Some of those complications might be technical, indicating an opportunity to improve results after those procedures. However, this finding highlights the complexity of those procedures, which can translate to higher morbidity and/or mortality.

The freedom from all-cause cardiac reoperation in our series was $60 \%$ at 10 years. Early-phase reoperation risk was mainly related to recurrent arch obstruction, in addition to few reoperations for early LVOTO. Nonetheless, the incidence of arch reoperations in our series to date has been low, likely because of the routine use of patch for arch augmentation in all our patients. This approach is similar to that of other series that have shown use of the patch at the time of IAA repair to be associated with lower risk of recurrent arch obstruction. ${ }^{3,4}$

In addition to early-phase cardiac reoperation risk, a persistent constant, and a late-phase cardiac reoperation risk occurred in our series. Freedom from cardiac reoperation was higher in patients who had standard IAA repair, compared with those who had more-complex concomitant LVOT procedures. Five-year freedom from cardiac reoperation was $80 \%$ for the standard IAA repair group, versus $56 \%$ for LVOT bypass and 53\% for LVOT enlargement. Although the bulk of reoperations in patients who had LVOT enlargement were for LVOTO, most of the late reoperations in the LVOT bypass group were for conduit change, indicating that although LVOT bypass procedures mitigated LVOTO risk, this was at the expense of a high requirement for right-side interventions.

Our current approach to neonates with IAA is to perform standard repair in those who have a LVOT diameter $>4.5 \mathrm{~mm}$, and LVOT bypass when the diameter is $<4$ $4.5 \mathrm{~mm}$. Given that the LVOT reoperation risk after LVOT enlargement is higher with conal resection, our procedure of choice in neonates who have small LVOT is staged LVOT bypass (the Norwood procedure); we reserve LVOT enlargement for neonates who require a return on cardiopulmonary bypass to address significant LVOTO after standard repair.

\section{CONCLUSIONS}

Interrupted aortic arch is a lifelong disease that is associated with late morbidity and reoperation risks, mainly owing to the development of LVOTO. Several morphologic factors are associated with small aortic valve, LVOT, and ascending aorta dimensions, and subsequently with increased LVOTO risk. Compared with historic reports, a selective management strategy customized to the degree of aortic valve and subaortic area narrowing has been shown in our experience to: (1) decrease the overall need for LVOT reoperation; (2) prolong the interval to LVOT reoperation; (3) decrease the complexity of LVOT reoperation; and (4) decrease mortality risk after LVOT reoperation. The effect of aortic valve and LVOT narrowing on increased LVOTO risk is neutralized with LVOT bypass procedures; however, it continues to be the highest after conal resection. Despite the mitigation of LVOTO risk with left ventricular bypass procedures, the tradeoff is a higher reoperation risk for conduit change.

\section{Conflict of Interest Statement}

Authors have nothing to disclose with regard to commercial support.

You can watch a Webcast of this AATS meeting presentation by going to: http://webcast.aats.org/2015/Video/ Tuesday/04-28-15_6A_1420_Kanter.mp4.

\section{References}

1. Jonas RA, Quaegebeur JM, Kirklin JW, Blackstone EH, Daicoff G. Outcomes in patients with interrupted aortic arch and ventricular septal defect: a multiinstitutional study. Congenital Heart Surgeons' Society. J Thorac Cardiovasc Surg. 1994;107:1099-113.

2. Schreiber C, Eicken A, Vogt M, Günther T, Wottke M, Thielmann M, et al. Repair of interrupted aortic arch: results after more than 20 years. Ann Thorac Surg. 2000;70:1896-9.

3. Tchervenkov CI, Jacobs JP, Sharma K, Ungerleider RM. Interrupted aortic arch: surgical decision making. Semin Thorac Cardiovasc Surg Pediatr Card Surg Аnпu. 2005;92-102.

4. McCrindle BW, Tchervenkov CI, Konstantinov IE, Williams WG, Neirotti RA, Jacobs ML, et al. Risk factors associated with mortality and interventions in 472 neonates with interrupted aortic arch: a Congenital Heart Surgeons' Society study. J Thorac Cardiovasc Surg. 2005;129:343-50.

5. Luciani GB, Ackerman RJ, Chang AC, Wells WJ, Starnes VA. One-stage repair of interrupted aortic arch, ventricular septal defect, and subaortic obstruction in the neonate: a novel approach. J Thorac Cardiovasc Surg. 1996;111:348-58.

6. Brown JW, Ruzmetov M, Okada Y, Vijay P, Rodefeld MD, Turrentine MW. Outcomes in patients with interrupted aortic arch and associated anomalies: a 20year experience. Eur J Cardiothorac Surg. 2006;29:666-73.

7. Hussein A, Iyengar AJ, Jones B, Donath SM, Konstantinov IE, Grigg LE, et al Twenty-three years of single-stage end-to-side anastomosis repair of interrupted aortic arches. J Thorac Cardiovasc Surg. 2010;139:942-7; discussion 948.

8. Morales DL, Scully PT, Braud BE, Booth JH, Graves DE, Heinle JS, et al. Interrupted aortic arch repair: Aortic arch advancement without a patch minimizes arch reinterventions. Ann Thorac Surg. 2006;82:1577-83; discussion 1583-4.

9. Jacobs ML, Chin AJ, Rychik J, Steven JM, Nicolson SC, Norwood WI. Interrupted aortic arch. Impact of subaortic stenosis on management and outcome. Circulation. 1995;92(9 Suppl):II128-31.

10. Suzuki T, Ohye RG, Devaney EJ, Ishizaka T, Nathan PN, Goldberg CS, et al. Selective management of the left ventricular outflow tract for repair of interrupted aortic arch with ventricular septal defect: management of left ventricular outflow tract obstruction. J Thorac Cardiovasc Surg. 2006;131:779-84.

11. Chen PC, Cubberley AT, Reyes K, Zurakowski D, Baird CW, Pigula FA, et al Predictors of reintervention after repair of interrupted aortic arch with ventricular septal defect. Ann Thorac Surg. 2013;96:621-8.

12. Fulton JO, Mas C, Brizard CP, Cochrane AD, Karl TR. Does left ventricular outflow tract obstruction influence outcome of interrupted aortic arch repair? Ann Thorac Surg. 1999;67:177-81.

13. Jegatheeswaran A, McCrindle BW, Blackstone EH, Jacobs ML, Lofland GK Austin EH III, et al. Persistent risk of subsequent procedures and mortality in 
patients after interrupted aortic arch repair: a Congenital Heart Surgeons' Society study. J Thorac Cardiovasc Surg. 2010;140:1059-75.

14. Alsoufi B, Karamlou T, McCrindle BW, Caldarone CA. Management options in neonates and infants with critical left ventricular outflow tract obstruction. Eur J Cardiothorac Surg. 2007;31:1013-21.

15. Salem MM, Starnes VA, Wells WJ, Acherman RJ, Chang RK, Luciani GB, et al. Predictors of left ventricular outflow obstruction following single-stage repair of interrupted aortic arch and ventricular septal defect. Am J Cardiol. 2000;86: 1044-7.

16. Geva T, Hornberger LK, Sanders SP, Jonas RA, Ott DA, Colan SD. Echocardiographic predictors of left ventricular outflow tract obstruction after repair of interrupted aortic arch. J Am Coll Cardiol. 1993;22:1953-60.

17. Hirata Y, Quaegebeur JM, Mosca RS, Takayama H, Chen JM. Impact of aortic annular size on rate of reoperation for left ventricular outflow tract obstruction after repair of interrupted aortic arch and ventricular septal defect. Ann Thorac Surg. 2010;90:588-92.

18. Apfel HD, Levenbraun J, Quaegebeur JM, Allan LD. Usefulness of preoperative echocardiography in predicting left ventricular outflow obstruction after primary repair of interrupted aortic arch with ventricular septal defect. Am J Cardiol. 1998;82:470-3.

19. Yasui H, Kado H, Nakano E, Yonenaga K, Mitani A, Tomita Y, et al. Primary repair of interrupted aortic arch and severe aortic stenosis in neonates. $J$ Thorac Cardiovasc Surg. 1987;93:539-45.

20. Hickey EJ, Yeh T Jr, Jacobs JP, Caldarone CA, Tchervenkov CI, McCrindle BW, et al. Ross and Yasui operations for complex biventricular repair in infants with critical left ventricular outflow tract obstruction. Eur J Cardiothorac Surg. 2010; 37:279-88.

21. Gruber PJ, Fuller S, Cleaver KM, Abdullah I, Gruber SB, Nicolson SC, et al. Early results of single-stage biventricular repair of severe aortic hypoplasia or atresia with ventricular septal defect and normal left ventricle. J Thorac Cardiovasc Surg. 2006;132:260-3.

22. Alsoufi B, Al-Halees Z, Manlhiot C, Awan A, Al-Ahmadi M, McCrindle BW, et al. Intermediate results following complex biventricular repair of left ventricular outflow tract obstruction in neonates and infants. Eur J Cardiothorac Surg. 2010;38:431-8.

23. Pearl JM, Cripe LW, Manning PB. Biventricular repair after Norwood palliation. Ann Thorac Surg. 2003;75:132-6.

24. Fadel BM, Manlhiot C, Al-Halees Z, Di Salvo G, Al-Ahmadi M, McCrindle B, et al. The fate of the neoaortic valve and root after the modified Ross-Konno procedure. J Thorac Cardiovasc Surg. 2013;145:430-7.

25. Kanter KR, Kirshbom PM, Kogon BE. Biventricular repair with the Yasui operation (Norwood/Rastelli) for systemic outflow tract obstruction with two adequate ventricles. Ann Thorac Surg. 2012;93:1999-2005.

26. Ohye RG, Kagisaki K, Lee LA, Mosca RS, Goldberg CS, Bove EL. Biventricular repair for aortic atresia or hypoplasia and ventricular septal defect. J Thorac Cardiovasc Surg. 1999;118:648-53.

27. Alsoufi B, Al-Halees Z, Manlhiot C, McCrindle BW, Al-Ahmadi M, Sallehuddin A, et al. Mechanical valves versus the Ross procedure for aortic valve replacement in children: propensity-adjusted comparison of long-term outcomes. J Thorac Cardiovasc Surg. 2009;137:362-70.e9.

28. Nathan M, Rimmer D, del Nido PJ, Mayer JE, Bacha EA, Shin A, et al. Aortic atresia or severe left ventricular outflow tract obstruction with ventricular septal defect: results of primary biventricular repair in neonates. Ann Thorac Surg. 2006;82:2227-32.

29. Ohye RG, Gomez CA, Ohye BJ, Goldberg CS, Bove EL. The Ross/Konno procedure in neonates and infants: intermediate-term survival and autograft function. Ann Thorac Surg. 2001;72:823-30.

30. Alsoufi B, Awan A, Al-Omrani A, Al-Ahmadi M, Canver CC, Bulbul Z, et al. The Rastelli procedure for transposition of the great arteries: Resection of the infundibular septum diminishes recurrent left ventricular outflow tract obstruction risk. Ann Thorac Surg. 2009;88:137-42.

Key Words: interrupted aortic arch, left ventricular outflow tract obstruction

\section{Discussion}

Dr J. Hirsch-Romano (Ann Arbor, Mich). Dr Kanter: Thank you very much for your excellent presentation of your study results. And again, congratulations go to Dr Alsoufi for his extreme productivity at this meeting, which has resulted in his inability to present this today.

I appreciated the opportunity to review the manuscript in advance. As you have described, cases of IAA and ventricular septal defect are often complex, and they have a high likelihood of requiring reoperation, which is an important point to discuss when initially counseling families.

I have 3 questions for you: First, you conclude that the risk of LVOTO is higher with LVOT bypass procedures, such as the Yasui operation or a staged approach with the Norwood procedure. For patients with marginal aortic valve size or other issues, such as low birth weight or prematurity, we have been performing a hybrid stage I palliation. For many of these patients, we ultimately have been able to perform a standard repair, or for those whose valves remain marginal in size, a delayed Norwood-Rastelli procedure at an older patient age, somewhat similar to your staged Norwood-Rastelli approach. Have you considered this approach for patients for whom you wish to perform an LVOT bypass procedure, as a means to avoid a large cardiopulmonary bypass operation when they are newborns?

Dr Kanter. No, we have not. That certainly is an alternative strategy. As you can see, the number of primary Yasui operations is low: 3 of 17. Fourteen of 17 of the Yasui procedures were staged. Although all of them survived, the hospital stay was much longer for those who received the procedure as the primary repair. None of our patients treated with a staged strategy had interstage deaths from the Norwood procedure to the repair. Certainly, a hybrid approach would achieve the same result, but in our experience, a standard Norwood procedure, with a later Rastelli-type approach seems to be successful.

Dr Hirsch-Romano. We are certainly seeing in some of those patients some actual integral growth of the aortic valve, pushing them into a primary repair group versus a Norwood-Rastelli procedure.

Dr Kanter. One of the 17 had enough growth that we were able to just close the ventricular septal defect and do a subaortic resection. However, that was the 1 patient in the Yasui operation group who needed subsequent LVOTO relief.

Dr Hirsch-Romano. The next question is: What are the criteria that you used to determine who will require an LVOT bypass reoperation? You have a significant amount of morphologic data available within this study. Did you consider creating a discrete scoring system to allocate patients to the different groups, or do you rely on the echo "eyeball test" that most of us still rely on?

Dr Kanter. For the patients who require LVOT reoperation, we use...

Dr Hirsch-Romano. No, the bypass operation-deciding who is going to get a primary repair versus a bypass. 
Dr Kanter. Got it. Sometimes it is very, very easy. If the aortic valve is $3 \mathrm{~mm}$, it is easy. So basically, if the $z$-score is $\geq-2$, then we will do a standard repair; if it is $\leq-3$, then we will do the bypass operation; if it is between -2 and -3 , it depends on how we feel that day, and what things look like.

Looking at absolute numbers, if the aortic valve or the LVOT is $\geq 5 \mathrm{~mm}$, we will clearly do a standard repair; for $<4 \mathrm{~mm}$, we will do a staged approach; and between 4 and $5 \mathrm{~mm}$, it depends what day of the week it is. So we have not formalized our selection criteria. You are right-it is a lot of eyeballing.

Dr Hirsch-Romano. My final question is: Based on your results, have you abandoned the conal resection, the socalled LVOT enlargement, for a bypass procedure for those patients with small but adequate outflow tracts, or do you just counsel those families that those patients are at high risk for LVOTO later on?

Dr Kanter. We have pretty much abandoned it, except for the occasions when we think that we are going to get in there, that it is going to be okay, and then as we do it, we realize that there is a big muscle bar underneath there. But if we get the very small LVOT, we will go to the LVOT bypass, the Yasui approach.

Dr Hirsch-Romano. Thank you again for a well prepared presentation and manuscript.

Dr F. Lacour-Gayet (London, United Kingdom). I really enjoyed your beautiful presentation and your good result.

But I want to ask you to elaborate on the choice of the Yasui versus the Ross-Konno operation in this patient. The Ross-Konno operation, done either primarily or staged, I think, offers 3 major advantages compared with the Yasui. First, it reconstructs a beautiful left outflow tract; it is not a complex aberrant subclavian subaortic obstruction. Second, the ventricular septal defect is a real problem in this patient, and in the long term, they can really stenose and be obstructed. Third, when you place a right-ventricle-to-pulmonary-artery conduit using a Ross-Konno procedure, it is an anatomic place that is not compressed by the sternum.

So my question for you is: Why do you prefer the Yasui to the Ross-Konno procedure in these patients?

Dr Kanter. I think that is a terrific question. First of all, in the reoperations on the standard group, in those who developed LVOTO, several eventually underwent the Ross-Konno procedure. However, we have been unwilling to do a primary Ross-Konno procedure with IAA. What you are asking is if we are doing a primary Norwood procedure, and then need to do a second operation, why not do a Ross-Konno procedure, rather than doing a Rastelli. I think that option is very viable, and probably superior because of the pathway. You are still stuck with a right ventricular pulmonary artery conduit, but it is not bulging out. So perhaps for the next one we do, we will do a Ross-Konno procedure. I think that is a good suggestion. I think that is probably an anatomically better solution than the Rastelli type that we currently use.
Dr Lacour-Gayet. What about this group of patients that we see more and more, who have IAA type B, with aberrant right subclavian artery, with a very small aortic annulus$3 \mathrm{~mm}$ or so. The question is what to do in the neonatal period. Instead of doing what you call a Norwood procedure, what about doing a hybrid procedure, with stenting of the duct to give the patient the opportunity to grow, and then at the second stage, a Ross-Konno operation? Do you think there is a rationale for using this approach, or not?

Dr Kanter. A large percentage of the patients who had the LVOT bypass group had type B interruption, with an aberrant right subclavian artery. I think that you are asking the exact same question that Jenna asked, which is: Why not do a hybrid approach and then come back and do a RossKonno procedure? That is a possibility, but it is not the approach we have taken. I think we need to examine our strategy for those severe LVOTO patients, and ask whether the ultimate operation, instead of being a Rastelli procedure, should be a Ross-Konno procedure.

Dr E. Belli (Massy, France). Kirk, there is a subgroupthe patients without conal septum, with IAA and doubly committed ventricular septal defect. Probably, in this group of patients, the indication criteria exclude the subaortic area, and only the annulus size counts. In addition, the primary Ross procedure is quite complicated. Would the Yasui operation option, either primarily or after the Norwood procedure, or after a hybrid, be likely to be the best solution for this group of patients, given that you do not have a conal septum, so potentially the ventricular septal defect will remain large, and it is more straightforward to tunnel to the pulmonary artery?

Dr Kanter. I do not think we had any patients in this series who had a doubly committed subarterial ventricular septal defect. But those points are valid.

Dr J. Quintessenza (St Petersburg, Fla). Very nice presentation. You guys do really great work. My question refers to the following: Was there any correlation between morphology type $\mathrm{A}, \mathrm{B} 1, \mathrm{~B} 2$, or $\mathrm{C}$ with the patients who developed subaortic outflow tract obstruction after primary repair? Can you tease that out at all?

Dr Kanter. The standard repair groups had fewer type B's than the other 2 groups (statistically different), but we were not able to see a correlation between the subsequent development of LVOTO and which type of IAA it was. So I do not have the answer to that.

Dr Quintessenza. The thought is that, for a type A, for eg, with all the arch vessel flow going through the aorta during fetal development-is that morphologic type less predisposed to a LVOTO later? That analysis might help determine the most appropriate initial surgical strategy.

Dr Kanter. I bet you are right. But the problem is with the numbers: We cannot come up with a statistical analysis that would be valid. But I agree that that makes sense. 

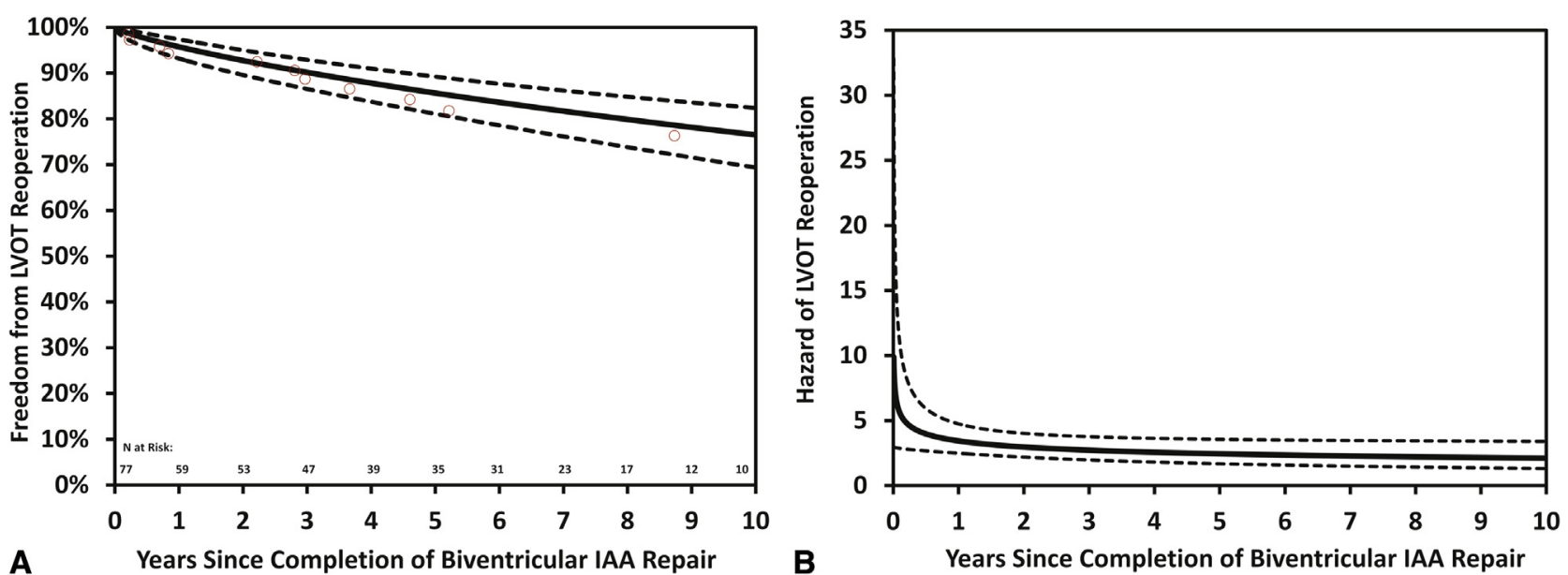

FIGURE E1. A, Parametric freedom from LVOT reoperation and (B) risk hazard of LVOT reoperation after completion of biventricular IAA repair. The solid lines in the parametric model represent parametric point estimates, and the dashed lines enclose the $95 \%$ confidence interval. Circles represent nonparametric estimates. LVOT, Left ventricular outflow tract; IAA, interrupted aortic arch.

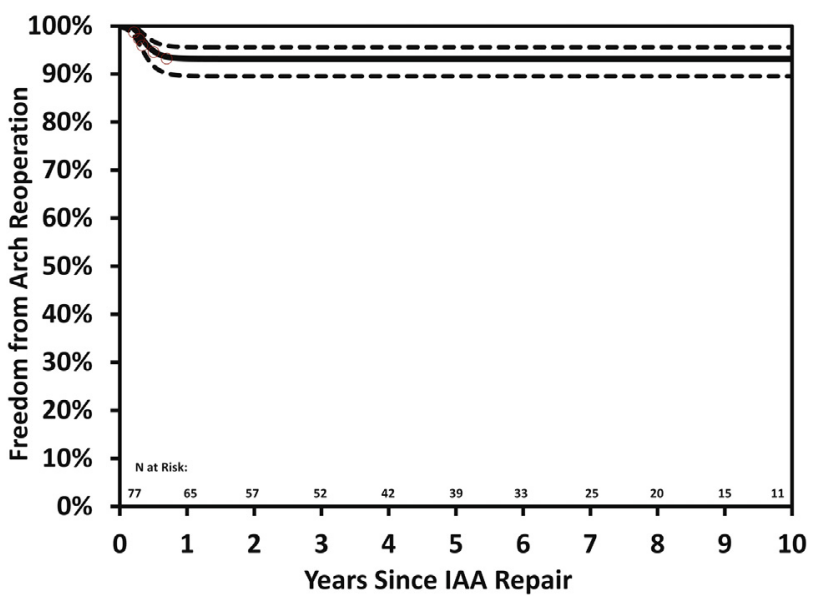

FIGURE E2. Parametric freedom from arch reoperation after IAA repair. The solid lines in the parametric model represent parametric point estimates, and the dashed lines enclose the $95 \%$ confidence interval. Circles represent nonparametric estimates. IAA, Interrupted aortic arch. 

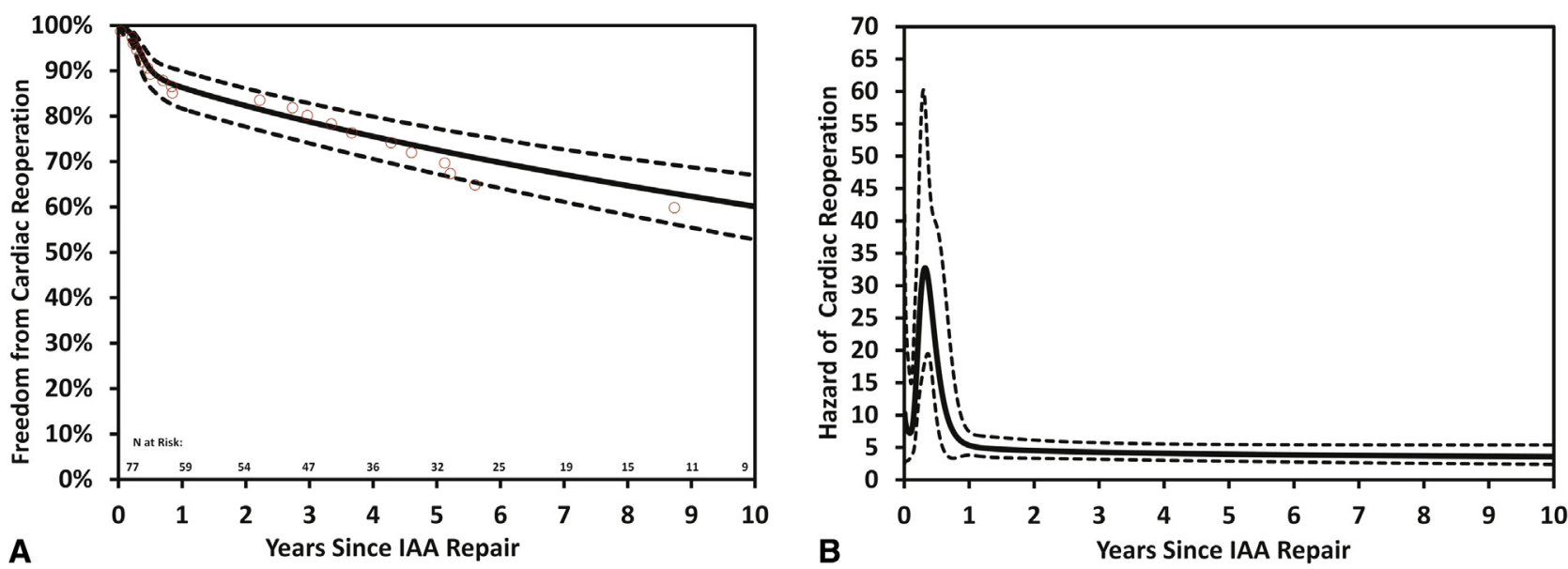

FIGURE E3. A, Parametric freedom from all-cause cardiac reoperation, and (B) risk hazard of all-cause cardiac reoperation after IAA repair. The solid lines in the parametric model represent parametric point estimates, and the dashed lines enclose the $95 \%$ confidence interval. Circles represent nonparametric estimates. IAA, Interrupted aortic arch.
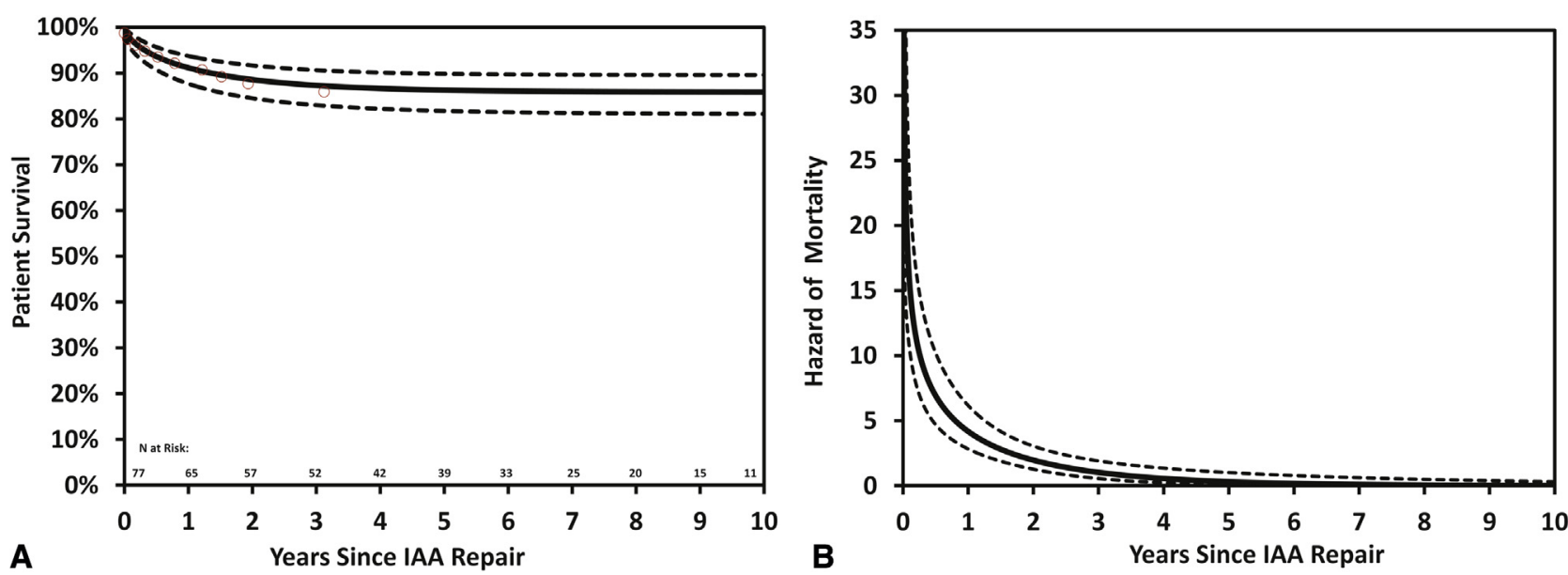

FIGURE E4. A, Parametric survival and (B) risk hazard of death after IAA repair. The solid lines in the parametric model represent parametric point estimates, and the dashed lines enclose the $95 \%$ confidence interval. Circles represent nonparametric estimates. IAA, Interrupted aortic arch. 